\title{
Stopping Renin-Angiotensin System Inhibitors in Chronic Kidney Disease: Predictors of Response
}

\author{
Anderson Roman Gonçalves ${ }^{a}$ Arif Khwaja ${ }^{b}$ Aimun K. Ahmed ${ }^{b}$ \\ Mohsen El Kossi ${ }^{b}$ Meguid El Nahas ${ }^{b}$

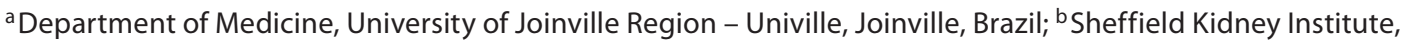 \\ Northern General Hospital, Sheffield, UK
}

\section{Key Words}

Chronic kidney disease $\cdot$ Renin-angiotensin system inhibitors • Predictors

\begin{abstract}
Background/Aims: Renin-angiotensin system (RAS) inhibitors are considered first-line agents for hypertensive patients with progressive chronic kidney disease (CKD). In a previous study, we showed that stopping RAS inhibitors increased estimated glomerular filtration rate (eGFR) in a significant number of advanced CKD patients. The present study tries to address who would benefit and whether this benefit is predictable. Methods: Forty-three CKD stage 4 patients had RAS inhibitors stopped and were followed for at least 24 months. Compared outcome groups were 'alive', 'renal replacement therapy (RRT)' or 'died'. Improvement in eGFR was used in a receiver-operating characteristic curve and finds the best predictor for surviving without RRT. Results: Patients who survived without RRT were all hypertensive and had a higher eGFR increment after stopping the drugs. Those with eGFR improvement $\geq 5 \mathrm{ml} / \mathrm{min} / 1.73 \mathrm{~m}^{2}$ were the most likely to survive long term without RRT (logrank test, $p=0.03$ ). They had a significant increment in blood pressure that correlated with eGFR improvement $(r=0.403$,
\end{abstract}

$p=0.013)$. Conclusion: A significant increase in eGFR after stopping RAS inhibitors suggests that long-term survival without RRT is more likely. Our findings question the universal preemptive indication of RAS inhibitors in advanced CKD and suggest that they can be safely stopped, at least in some patients.

Copyright $\odot 2011$ S. Karger AG, Basel

\section{Introduction}

Use of renin-angiotensin system (RAS) inhibitors is perceived as the cornerstone of treatment of progressive and proteinuric nephropathies including diabetic nephropathy. RAS inhibitors are considered the first line of treatment for hypertension in the presence of chronic kidney disease (CKD) in most guidelines [1, 2]. A small number of studies in advanced CKD (stage 4) show some persistent protective effect of these agents in avoiding renal replacement therapy (RRT) [3-6], but the results are only consistent when the reduced estimated glomerular filtration rate (eGFR) is associated with significant proteinuria [7-9]. There is little doubt that overall angiotensin-converting enzyme (ACE) inhibitors and angiotensin $\mathrm{T} 1$ receptor blockers (ARBs) have some protective effect

\section{KARGER}

Fax +4161306 1234 E-Mail karger@karger.ch www.karger.com
Anderson Roman Gonçalves, $\mathrm{MD}, \mathrm{PhD}$

Department of Medicine, University of Joinville Region - Univille

Rua Paulo Malschitzki, n ${ }^{\circ}$ 10, Campus Universitário, Postal Box 246 Joinville, SC 89219-710 (Brazil)

Tel. +55 473461 9112, E-Mail anderson.roman@univille.edu.br 
on declining kidney function as shown in a number of studies over the last 25 years. However, critical analysis of some of the major studies cast some doubt on the validity of the generalization of this concept. For instance, a careful analysis of the data presented by the Ramipril Efficacy In Nephropathy (REIN) study of chronic non-diabetic nephropathies fail to show an overall effect of ramipril on the rate of decline of GFR [10]. Only subsequent subgroup analyses showed some benefit [5]. Also, a higher incidence of end-stage renal disease (ESRD) has been reported in diabetic patients persistently treated with ACE inhibitors [11]. Recently a post hoc analysis of the RENAAL trial showed that losartan was associated with a high risk of increased serum potassium levels, that in turn was associated with an increased risk of renal outcomes in patients with diabetes and nephropathy [12]. This may reflect the concern of using these agents in older patients with underlying cardiovascular disease (CVD) [13-15]. Consequently, in the majority of elderly CKD patients who are likely to have associated CVD, the renal benefit of RAS inhibitors, beyond cardiovascular protection, is a matter of debate [11, 13-16]. Further, there are some emerging reports showing that some patients with advanced renal insufficiency could benefit from stopping these agents and postponing RRT $[17,18]$.

In a small pilot observation, we recently noted that stopping RAS inhibitors increased eGFR in a significant number of patients [17]. This small study raised critical questions about who would benefit from stopping RAS inhibitors and whether this benefit is predictable. In order to answer these questions, we analyzed this database to look for predictors of improvement in the eGFR and risk of RRT or death.

\section{Patients and Methods}

This is an extension and analysis to a previously published pilot observational study [17]. The cohort represented 52 consecutive patients who were on RAS inhibitors and referred to the advanced kidney care clinic of the Sheffield Kidney Institute. We studied data for 43 patients as long-term follow-up data was missing for 9 patients. In summary, this is an observational report of 43 patients who were on inhibitors of RAS (17 females and 26 males), mean age $69.9 \pm 13.0$ years, who were referred to the advanced kidney care clinic of the Sheffield Kidney Institute in 2005-2006 in anticipation of starting RRT. The average eGFR was $19.3 \pm 8.1 \mathrm{ml} / \mathrm{min} / 1.73 \mathrm{~m}^{2}$ at presentation to the clinic. Proteinuric kidney disease was defined as presence of urine protein:creatinine ratio $\geq 100 \mathrm{mg} / \mathrm{mmol}$. Associated CVD was considered as a presence of history or signs of ischemic heart disease, cerebral or peripheral vascular disease or congestive cardiac failure.

Predicting Response after Stopping RAS Inhibitors
Patients included for analysis were those who had stopped RAS inhibitors and were followed for at least 24 months, up to discharge (censured), start of RRT or death. Some patients were followed for a longer period (median follow-up 24 months). For the purpose of analysis, patients were divided into three groups based on the outcomes: Survivors, those who survived without RRT; RRT, those who started RRT, and Died, those who died before RRT. For clarity, blood pressure and eGFR data were named as before if they were obtained 1-3 months before stopping RAS inhibitors; as baseline, if obtained at the time of stopping, and as after, if obtained 1-3 months after baseline. The clinical management of the patients as RAS inhibitors were stopped is described in a previous study [17].

Serum creatinine was measured by the standard autoanalyzer technique. The four-variable MDRD formula was used to obtain eGFR. Blood pressure measurements were performed routinely according to standard procedures in all patients with an automatic Dinamap XL Model 9300 series device (Johnson \& Johnson Medical, Tampa, Fla., USA).

\section{Statistical Analysis}

Categorical variables were compared by $\chi^{2}$ test. One-way ANOVA with Tukey honest significance test or Dunnett's T3 post hoc analyses was used to compare between-group characteristics, according to variance. A paired t test was conducted to assess within-group differences between periods. A multinomial logistic regression was conducted including baseline variables with significant differences between outcome groups. A receiver-operating characteristic (ROC) curve was used to analyze the after eGFR improvement from baseline and find the best predictor point to the outcome 'survival without RRT' [19]. To evaluate the time-to-event effect, a Kaplan-Meier curve was built with the predicted eGFR change as grouping variable. $\mathrm{p}<0.05$ was considered statistically significant.

\section{Results}

The characteristics of each outcome group are shown in table 1. Survivors had higher before and baseline eGFR than RRT, were mostly non-proteinuric and were all hypertensive. RRT had a lower before and baseline eGFR and were mostly proteinuric. Died were older, had a higher before and baseline eGFR than RRT and only a small percentage had proteinuria. Survivors and Died had a significant decrease in before to baseline eGFR, but only Survivors had a significant increase in the after eGFR ( $\mathrm{p}<$ 0.05). Functional improvement was absent in RRT and Died (fig. 1). The multinomial logistic regression analysis using age, gender, before and baseline eGFR, presence of hypertension and proteinuria, was unable to predict any of the three outcome groups.

For the question 'who would benefit from stopping RAS inhibitors', we analyzed the area under the ROC curve (AUC) for eGFR improvement as absolute ( $\mathrm{ml} /$ 
Table 1. Baseline and follow-up characteristics according to outcome group

\begin{tabular}{|c|c|c|c|}
\hline Characteristics & Survivors $(\mathrm{n}=21)$ & $\mathrm{RRT}(\mathrm{n}=13)$ & $\operatorname{Died}(\mathrm{n}=9)$ \\
\hline Age, years & $73 \pm 8$ & $60 \pm 18$ & $77 \pm 5^{*,+}$ \\
\hline Male, \% & 42.9 & $84.6^{*}$ & 66.7 \\
\hline Median follow-up (range), months & $32(4-71)$ & $12(1-39)$ & $17(1-60)$ \\
\hline $\begin{array}{l}\text { eGFR, } \mathrm{ml} / \mathrm{min} / 1.73 \mathrm{~m}^{2} \\
\text { Before }\end{array}$ & $23 \pm 8^{\dagger}$ & $13 \pm 6$ & $22 \pm 8^{\dagger}$ \\
\hline Baseline & $18 \pm 6^{\dagger, \S}$ & $11 \pm 3$ & $17 \pm 7^{\dagger, \S}$ \\
\hline After & $26 \pm 8^{\ddagger}$ & $13 \pm 4^{*}$ & $20 \pm 6$ \\
\hline \multicolumn{4}{|l|}{ SBP, mm Hg } \\
\hline Baseline & $133 \pm 16$ & $132 \pm 19$ & $132 \pm 30$ \\
\hline After & $150 \pm 20^{\ddagger}$ & $149 \pm 18^{\ddagger}$ & $127 \pm 16^{*, \dagger}$ \\
\hline$\Delta$ (after - baseline $)$ & $16.6 \pm 15$ & $14.2 \pm 17.8$ & $-1.6 \pm 19.6$ \\
\hline \multicolumn{4}{|l|}{ DBP } \\
\hline Baseline & $68 \pm 9$ & $70 \pm 11$ & $75 \pm 16$ \\
\hline After & $76 \pm 9$ & $83 \pm 13$ & $67 \pm 4^{*, \dagger}$ \\
\hline$\Delta$ (after - baseline $)$ & $8.2 \pm 8.6$ & $10.9 \pm 10.2$ & $-4.2 \pm 11.8^{*, \dagger}$ \\
\hline \multicolumn{4}{|l|}{ MAP } \\
\hline Baseline & $93 \pm 9$ & $96 \pm 11$ & $92 \pm 17$ \\
\hline After & $99 \pm 6$ & $104 \pm 9$ & $90 \pm 7^{*,+}$ \\
\hline Proteinuria, \% & $28.6^{\dagger}$ & 76.9 & $16.7^{\dagger}$ \\
\hline Diabetes, \% & 61.9 & 55.6 & 38.5 \\
\hline Hypertension, \% & 100 & $66.7^{*}$ & $76.9^{*}$ \\
\hline Previous CVD, \% & 42.9 & 55.6 & 61.5 \\
\hline
\end{tabular}

${ }^{*} \mathrm{p}<0.05$ vs. survivors; ${ }^{\dagger} \mathrm{p}<0.05$ vs. $R R T ;{ }^{\ddagger} \mathrm{p}<0.05$ vs. baseline $;{ }^{\circledR} \mathrm{p}<0.05$ vs. before.

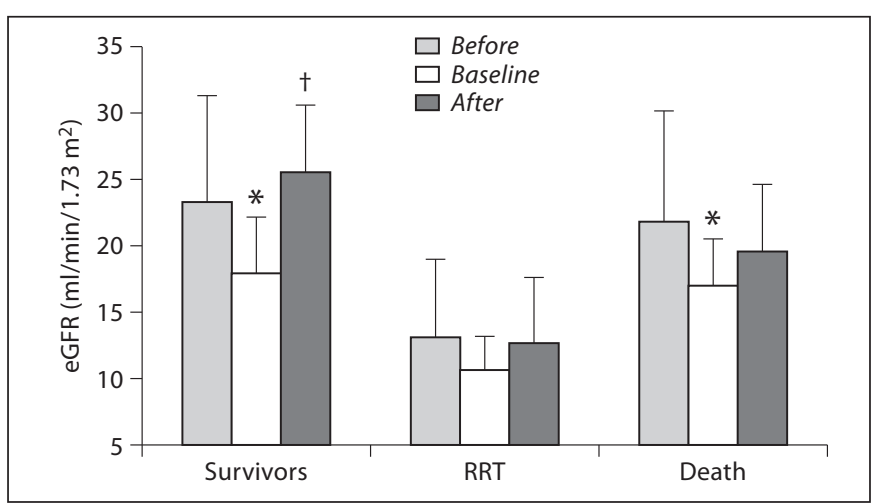

Fig. 1. eGFR variation according to group outcome. Mean eGFR values are before, baseline and after according to the period when RAS inhibitors were stopped. The values are mean $\pm \mathrm{SD} .{ }^{*} \mathrm{p}<$ 0.05 vs. before ${ }^{\dagger} \mathrm{p}<0.05$ vs. baseline.

$\min / 1.73 \mathrm{~m}^{2}$ ) or percentage (\%) changes from baseline to after periods in order to discriminate the outcome 'surviving without RRT'. The absolute eGFR improvement performed better than percentage eGFR improvement with an AUC of $0.720(\mathrm{p}=0.014)$ and $0.667(\mathrm{p}=0.061)$, respectively. The best predictor point was between 4.5 and $5.5 \mathrm{ml} / \mathrm{min} / 1.73 \mathrm{~m}^{2}$ of improvement. Therefore, an increase in the after eGFR from baseline of $\geq 5 \mathrm{ml} /$ $\mathrm{min} / 1.73 \mathrm{~m}^{2}$ was associated with survival without RRT in a time-to-event Kaplan-Meier analysis (log-rank test, $\mathrm{p}=$ 0.03 ), as shown in figure 2.

The second question about predictability of the benefit (eGFR increment of at least $5 \mathrm{ml} / \mathrm{min} / 1.73 \mathrm{~m}^{2} 1-3$ months after stopping RAS inhibitors) was addressed by searching variables that differentiate the two resulting groups: $\Delta$ eGFR $<5$, those with eGFR increment $<5 \mathrm{ml} / \mathrm{min} /$ $1.73 \mathrm{~m}^{2}$, and $\Delta \mathrm{eGFR} \geq 5$, with eGFR increment $\geq 5 \mathrm{ml} /$ $\min / 1.73 \mathrm{~m}^{2}$ (table 2). The variation in systolic blood pressure (SBP) and diastolic blood pressure (DBP) during the first 3 months after stopping RAS inhibitors were significantly higher in those in $\triangle \mathrm{eGFR} \geq 5$. The eGFR increment was correlated with SBP increment $(\mathrm{r}=0.403, \mathrm{p}=$ 0.013 ) (fig. 3). Of note, both groups had a significant decrease in eGFR from the previous 3 months to baseline $\left(21 \pm 8\right.$ to $17 \pm 6 \mathrm{ml} / \mathrm{min} / 1.73 \mathrm{~m}^{2}$ in $\Delta$ eGFR $<5 ; 21 \pm 9$ to $14 \pm 6 \mathrm{ml} / \mathrm{min} / 1.73 \mathrm{~m}^{2}$ in $\Delta \mathrm{eGFR} \geq 5$ ). As expected, it was only in $\triangle \mathrm{eGFR} \geq 5$ that the eGFR increased in the after period $\left(25 \pm 9 \mathrm{ml} / \mathrm{min} / 1.73 \mathrm{~m}^{2}, \mathrm{p}<0.001\right)$. Com- 


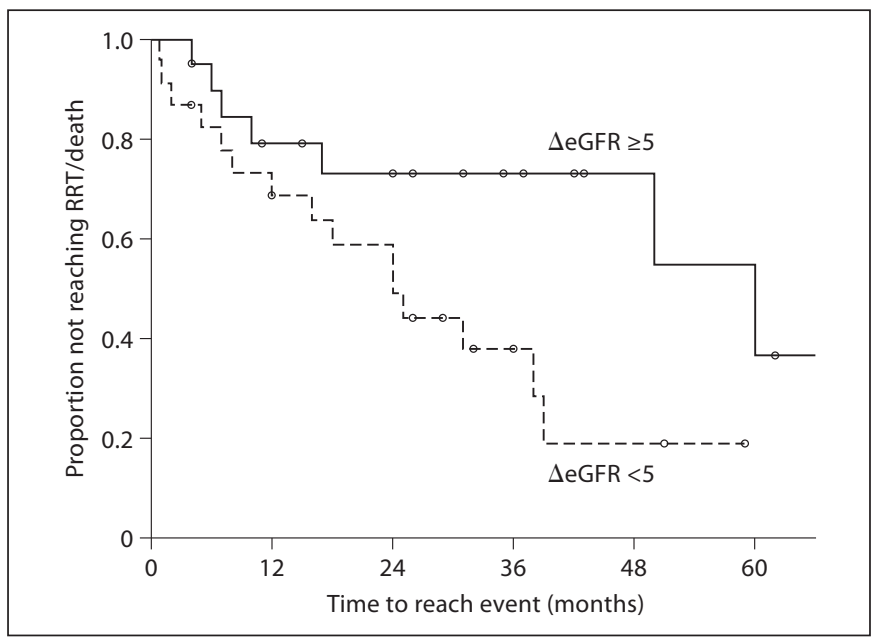

Fig. 2. Kaplan-Meier estimates of patients surviving without RRT. Time zero is when RAS inhibitors were stopped. Events were RRT or death. Solid line: patients with baseline to after eGFR increment $\geq 5 \mathrm{ml} / \mathrm{min} / 1.73 \mathrm{~m}^{2}(\Delta \mathrm{eGFR} \geq 5)$; dashed line: those with eGFR increment $<5 \mathrm{ml} / \mathrm{min} / 1.73 \mathrm{~m}^{2}(\Delta \mathrm{eGFR}<5)$. log-rank test, $\mathrm{p}=0.03$.

pared with baseline values, the eGFR increment and blood pressure (SBP, DBP and MAP) were significantly higher in the $\triangle \mathrm{eGFR} \geq 5$ group.

\section{Discussion}

This study builds on, and is derived from, our pilot study showing that stopping RAS inhibitors in advanced renal insufficiency leads to an overall improvement in renal function and delay in the initiation of RRT [17]. In that study we clearly demonstrated an improvement or stabilization of GFR in most patients after stopping RAS inhibitors [17]. Here we attempt to identify those most likely to benefit from such an intervention. Thus the data presented here is quite distinct from the data in our pilot study. In particular, a significant increment of blood pressure after stopping RAS inhibitors correlates with a significant improvement in eGFR, suggesting that a significant number of the cohort on RAS inhibitors had hemodynamically significant renovascular disease. The baseline characteristics were not discriminative, but a short follow-up after stopping RAS inhibitors provided enough data. It appears that whilst the majority of patients have an increment in eGFR of more than $20 \%$, only those whose eGFR improves by at least $5 \mathrm{ml} / \mathrm{min} / 1.73 \mathrm{~m}^{2}$ during the first 3 months after stopping RAS inhibitors had a higher probability of surviving without RRT over

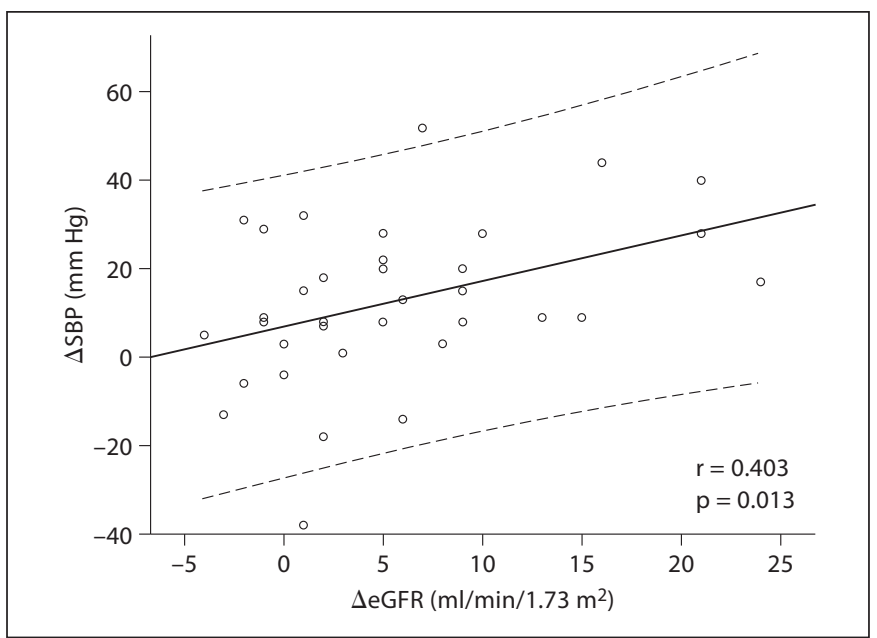

Fig. 3. Relationship between variation from baseline to after periods in eGFR ( $\triangle \mathrm{eGFR})$ and systolic blood pressure $(\Delta \mathrm{SBP})$. Baseline values were obtained when the RAS inhibitors were stopped; after values were obtained 1-3 months after stopping RAS inhibitors; variation $(\Delta)$ is after minus baseline value.

Table 2. Variables values according to eGFR increment group

\begin{tabular}{|c|c|c|}
\hline Characteristics & $\Delta \mathrm{eGFR}<5$ & $\Delta \mathrm{eGFR} \geq 5$ \\
\hline Age, years & $71 \pm 12$ & $69 \pm 14$ \\
\hline Male, \% & 73.9 & 45.0 \\
\hline \multicolumn{3}{|l|}{ Outcome } \\
\hline Alive/non-RRT & 8 & 13 \\
\hline RRT & 8 & 5 \\
\hline Death & 7 & 2 \\
\hline \multicolumn{3}{|l|}{$\mathrm{eGFR}, \mathrm{ml} / \mathrm{min} / 1.73 \mathrm{~m}^{2}$} \\
\hline Before & $21 \pm 8$ & $21 \pm 9$ \\
\hline Baseline & $17 \pm 6^{\dagger}$ & $14 \pm 6^{\dagger}$ \\
\hline After & $17 \pm 7^{\dagger}$ & $25 \pm 9^{*, \neq}$ \\
\hline \multicolumn{3}{|l|}{$\mathrm{SBP}, \mathrm{mm} \mathrm{Hg}$} \\
\hline Baseline & $135 \pm 21$ & $130 \pm 17$ \\
\hline After & $140 \pm 20$ & $151 \pm 19^{\dagger}$ \\
\hline$\Delta$ (after - baseline $)$ & $6.5 \pm 17.1$ & $19.4 \pm 15.8^{*}$ \\
\hline \multicolumn{3}{|l|}{$\mathrm{DBP}, \mathrm{mm} \mathrm{Hg}$} \\
\hline Baseline & $71 \pm 11$ & $69 \pm 11$ \\
\hline After & $73 \pm 9$ & $81 \pm 12^{*, \dagger}$ \\
\hline$\Delta$ (after - baseline $)$ & $2.1 \pm 11.2$ & $10.9 \pm 9.2^{*}$ \\
\hline \multicolumn{3}{|l|}{ MAP, mm Hg } \\
\hline Baseline & $95 \pm 12$ & $92 \pm 11$ \\
\hline After & $97 \pm 9$ & $102 \pm 8^{\dagger}$ \\
\hline Proteinuria, \% & 34.8 & 45.0 \\
\hline Diabetes, \% & 60.9 & 45.0 \\
\hline Hypertension, \% & 78.3 & 95.0 \\
\hline Previous CVD, \% & 60.9 & 40.0 \\
\hline
\end{tabular}

${ }^{*} \mathrm{p}<0.05$ vs. $\triangle e G F R<5 ;{ }^{\dagger} \mathrm{p}<0.05$ vs. before $;{ }^{\ddagger} \mathrm{p}<0.05$ vs. baseline. 
a 2-year period. Improved outcome in the group whose eGFR increased by more than $5 \mathrm{ml} / \mathrm{min} / 1.73 \mathrm{~m}^{2}$ coincided with a significant increase in blood pressure after stopping the RAS inhibitor.

Patients who proceeded to RRT (RRT) were different from those whose renal function improved in that they had lower eGFR at the time of discontinuation of the RAS inhibitor and failed to significantly increase their eGFR in response to this intervention. The more advanced stage of renal dysfunction in this subgroup may imply that there is a functional threshold beyond which functional recovery is less likely; CKD stage 5 rather than stage 4 . In fact, the evidence for an advantageous effect of ACE inhibitors in the late stages of CKD is weak.

For those who responded, the rapid decline in eGFR before discontinuation of the RAS inhibitor raises questions about the possibility of an acute on chronic additional insult such as hypovolemia, decompensated congestive cardiac failure, use of iodinated radiocontrast agents or nephrotoxic drugs, among others [20]. Whilst such an event has been ruled out in our careful analysis, it cannot be categorically excluded in a retrospective observational study. It is well documented that AKI can precipitate ESRD in patients with CKD and the use of ACE inhibitors in these mostly elderly patients can only exacerbate such an insult [21] - another reason to use inhibitors of RAS with caution in advanced stages of CKD in the elderly.

With the above in mind, Suissa et al. [11] have related long-term use of inhibitors of RAS with an increasing incidence of ESRD in diabetic patients. This was particularly true in those who remained on these agents to the bitter end; reduced, almost halving, of the risk was reported in those who stopped these agents after a while [11]. Of note a large percentage of our patients were older diabetic patients.

The adverse effects of RAS inhibitors on glomerular hemodynamics are well recognized and the improvement seen in GFR associated with stopping these drugs may simply reflect altered glomerular hemodynamics. This suggests that glomerular autoregulation is preserved and that restoration of angiotensin II mediated efferent arteriolar vasoconstriction improves renal function. It is known that long-term hypertension, advanced $\mathrm{CKD}$ and aging are followed by a progressive loss of autoregulation $[22,23]$. This may be compounded by the use of ACE inhibitors late in the course of CKD when residual renal function and avoidance of RRT depends on a small number of hyperfunctioning nephrons. In $\mathrm{CKD}$, it is generally accepted that eGFR could be re- duced by as much as $20-30 \%$ after starting RAS inhibitors, but information is lacking about the magnitude of functional recovery when these agents are discontinued. One would expect functional improvement to be more significant early in the course of CKD; this is what we seem to have observed albeit in a small sample size. When RAS inhibitors were stopped, calcium channel blockers (CCBs) were often used to control blood pressure. Whilst there is animal data, there is no human data to demonstrate that CCBs result in improvement in GFR. Therefore the observed increase in GFR is more likely to be due to stopping the RAS inhibitors and it is unlikely that starting CCBs per se would have improved GFR.

Our observation that those who improved are those whose blood pressure rose the most after stopping the RAS inhibitor is of considerable interest. Firstly, it may suggest that the beneficial effect of stopping the ACE inhibitor/ARB on renal function is not an agent-specific effect, but the consequence of increased blood pressure and consequent rise in perfusion pressure. Secondly, it suggests that perhaps current target blood pressure levels in CKD are too low for the aging CKD population. The majority of our patients were elderly and no distinction was made in our practice, based on applied guidelines, between target BP levels for younger and older CKD patients. Recent attention has been drawn to this important issue in CKD patients where the advantage of aggressive lowering of blood pressure has been questioned [24] and in ESRD patients where age, diabetes and lower blood pressure seemed to be detrimental [25].

Unsurprisingly proteinuric patients were more likely to require RRT. Of note, stopping ACE inhibitors in this group did not accelerate the rate of decline in eGFR nor did it increase the level of proteinuria [17]. It is well recognized that not all proteinuric CKD patients respond to these agents and that perhaps more attention should be paid to those who do not respond as increasing their inhibitors of RAS may seriously compromise their residual renal function with little or no benefit on proteinuria. Further, one wonders if such aggressive inhibition of RAS may underlie reports of hyperkalemia related to worsening of renal outcomes [12]. The concept that reduction of proteinuria is invariably protective of renal function may not always hold true as some studies showed that treating elderly and susceptible CKD patients with these agents can improve proteinuria while accelerating the decline of eGFR [26].

Our study has a number of serious limitations. It is a retrospective study, thus some data could be imprecise or 
missing. A significant number of patients whose renal function improved back to CKD stage $3 \mathrm{~A}$ or B were discharged, after a while, back to primary care thus limiting their follow-up data. We have conducted an observational study without a control group and therefore any interpretation of the data should be done with caution. It is not possible from the small number of patients studied and followed up to make sweeping conclusions about stopping RAS inhibitors and remission, ESRD or death. Some may argue that removing RAS inhibitors in patients with even advanced kidney disease is denying them 'renoprotection'. Whilst this may be theoretically true, the reality is that in this observational study, stopping these agents actually delayed the onset of RRT. Furthermore, the renoprotective effects of RAS inhibitors has predominantly been demonstrated in proteinuric kidney disease and whilst most of our patient group had non-proteinuric kidney disease and therefore may not derive 'renoprotection' from RAS inhibitors, particularly in advanced CKD.

Our findings question the universal preemptive indication of RAS inhibitors in advanced CKD and suggest that they can be safely stopped, at least in some patients. This observation should draw more attention and caution to the use of these agents in older patients with advanced $\mathrm{CKD}$. Also to draw attention to those who fail to respond in terms of proteinuria and the risks associated with their exposure to higher doses of these agents alone or in combination including that of hyperkalemia. We hope that our observation will trigger larger and randomized studies to answer the question of the utility and risk-benefit associated with inhibitors of RAS in advanced CKD proteinuric and otherwise. In particular, such trials will need to address whether any benefits in delaying dialysis with stopping RAS inhibitors are offset by adverse cardiovascular outcomes. It is important to recognize that most clinical trials showing the benefit of RAS inhibitors on cardiovascular outcomes excluded patients with advanced CKD $[27,28]$.

\section{Disclosure Statement}

The authors have no competing interests to declare.

\section{References}

$1 \mathrm{~K} / \mathrm{DOQI}$ clinical practice guidelines on hypertension and antihypertensive agents in chronic kidney disease. Am J Kidney Dis 2004;43:11-13.

2 National Collaborating Centre for Chronic Conditions: Chronic Kidney Disease: $\mathrm{Na}-$ tional Clinical Guideline for Early Identification and Management in Adults in Primary and Secondary Care. London, Royal College of Physicians, 2008.

-3 Hou FF, Zhang X, Zhang GH, Xie D, Chen PY, Zhang WR, Jiang JP, Liang M, Wang GB, Liu ZR, Geng RW: Efficacy and safety of benazepril for advanced chronic renal insufficiency. N Engl J Med 2006;354:131140.

-4 Levin A, Djurdjev O, Beaulieu M, Er L: Variability and risk factors for kidney disease progression and death following attainment of stage 4 CKD in a referred cohort. Am J Kidney Dis 2008;52:661-671.

5 Ruggenenti P, Perna A, Remuzzi G: ACE inhibitors to prevent end-stage renal disease: when to start and why possibly never to stop: a post-hoc analysis of the REIN trial results. J Am Soc Nephrol 2001;12:2832-2837.

-6 The GISEN Group (Gruppo Italiano di Studi Epidemiologici in Nefrologia): Randomised placebo-controlled trial of effect of ramipril on decline in glomerular filtration rate and risk of terminal renal failure in proteinuric, non-diabetic nephropathy. Lancet 1997;349: 1857-1863. 7 Kent DM, Jafar TH, Hayward RA, Tighi-
ouart H, Landa M, de Jong P, de Zeeuw D, Remuzzi G, Kamper AL, Levey AS, for the AIRPD Study Group: Progression risk, urinary protein excretion, and treatment effects of angiotensin-converting enzyme inhibitors in nondiabetic kidney disease. J Am Soc Nephrol 2007;18:1959-1965.

$\checkmark 8$ Lea J, Greene T, Hebert L, Lipkowitz M, Massry S, Middleton J, Rostand SG, Miller E, Smith W, Bakris GL, for the African American Study of Kidney Disease and Hypertension Study Group: the relationship between magnitude of proteinuria reduction and risk of end-stage renal disease: results of the African American Study of Kidney Disease and Hypertension. Arch Intern Med 2005; 165: 947-953.

\9 Obi Y, Kimura T, Nagasawa Y, Yamamoto R, Yasuda K, Sasaki K, Kitamura H, Imai E, Rakugi H, Isaka Y, Hayashi T: Impact of age and overt proteinuria on outcomes of stage 3 to 5 chronic kidney disease in a referred cohort. Clin J Am Soc Nephrol 2010;5:15581565.

10 Ruggenenti P, Perna A, Gherardi G, Garini G, Zoccali C, Salvadori M, Scolari F, Schena FP, Remuzzi G: Renoprotective properties of ACE inhibition in non-diabetic nephropa- thies with non-nephrotic proteinuria. Lancet 1999;354:359-364.

11 Suissa S, Hutchinson T, Brophy JM, Kezouh A: ACE inhibitor use and the long-term risk of renal failure in diabetes. Kidney Int 2006; 69:913-919.

12 Miao Y, Dobre D, Lambers Heerspink H, Brenner B, Cooper M, Parving HH, Shahinfar S, Grobbee D, de Zeeuw D: Increased serum potassium affects renal outcomes: a post-hoc analysis of the Reduction of Endpoints in NIDDM with the Angiotensin II Antagonist Losartan (RENAAL) trial. Diabetologia 2011;54:44-50.

13 Bakris GL: Does evidence support renin-angiotensin system blockade for slowing nephropathy progression in elderly persons? Ann Intern Med 2009;150:731-733.

14 O'Hare AM, Choi AI, Bertenthal D, Bacchetti P, Garg AX, Kaufman JS, Walter LC, Mehta KM, Steinman MA, Allon M, McClellan WM, Landefeld CS: Age affects outcomes in chronic kidney disease. J Am Soc Nephrol 2007; 18:2758-2765.

15 O’Hare AM, Kaufman JS, Covinsky KE, Landefeld CS, McFarland LV, Larson EB: Current guidelines for using angiotensinconverting enzyme inhibitors and angiotensin II-receptor antagonists in chronic kidney disease: is the evidence base relevant to older adults? Ann Intern Med 2009;150:717-724. 
-16 Rahman M, Pressel S, Davis BR, Nwachuku C, Wright JT Jr, Whelton PK, Barzilay J, Batuman V, Eckfeldt JH, Farber M, Henriquez M, Kopyt N, Louis GT, Saklayen M, Stanford C, Walworth C, Ward H, Wiegmann T, for the ALLHAT Collaborative Research Group: Renal outcomes in high-risk hypertensive patients treated with an angiotensin-converting enzyme inhibitor or a calcium channel blocker versus a diuretic: a report from the Antihypertensive and Lipid-Lowering Treatment to Prevent Heart Attack Trial (ALLHAT). Arch Intern Med 2005;165:936946.

-17 Ahmed AK, Kamath NS, El Kossi M, El Nahas AM: The impact of stopping inhibitors of the renin-angiotensin system in patients with advanced chronic kidney disease. Nephrol Dial Transplant 2010;25:39773982.

-18 Onuigbo M, Onuigbo N: Late-onset renal failure from angiotensin blockade (LORFFAB) in 100 CKD patients. Int Urol Nephrol 2008;40:233-239.

19 Swets JA: Measuring the accuracy of diagnostic systems. Science 1988;240:1285-1293.
20 Brown NJ, Vaughan DE: Angiotensin-converting enzyme inhibitors. Circulation 1998; 97:1411-1420.

21 Anderson S, Eldadah B, Halter JB, Hazzard WR, Himmelfarb J, Horne FM, Kimmel PL, Molitoris BA, Murthy M, O'Hare AM, Schmader KE, High KP: Acute kidney injury in older adults. J Am Soc Nephrol 2011;22: 28-38.

22 Hill GS: Hypertensive nephrosclerosis. Curr Opin Nephrol Hypertens 2008;17:266-270.

23 Zhou XJ, Rakheja D, Yu X, Saxena R, Vaziri ND, Silva FG: The aging kidney. Kidney Int 2008;74:710-720.

24 Appel LJ, Wright JT, Greene T, Agodoa LY, Astor BC, Bakris GL, Cleveland $\mathrm{WH}$ Charleston J, Contreras G, Faulkner ML, Gabbai FB, Gassman JJ, Hebert LA, Jamerson KA, Kopple JD, Kusek JW, Lash JP, Lea JP, Lewis JB, Lipkowitz MS, Massry SG, Miller ER, Norris K, Phillips RA, Pogue VA, Randall OS, Rostand SG, Smogorzewski MJ, Toto RD, Wang X: Intensive bloodpressure control in hypertensive chronic kidney disease. N Engl J Med 2010;363: 918-929.
25 Myers OB, Adams C, Rohrscheib MR, Servilla KS, Miskulin D, Bedrick EJ, Zager PG: Age, race, diabetes, blood pressure, and mortality among hemodialysis patients. J Am Soc Nephrol 2010;21:1970-1978.

26 The ONTARGET Investigators: Telmisartan, ramipril, or both in patients at high risk for vascular events. N Engl J Med 2008;358: 1547-1559.

27 Charytan D, Kuntz RE: The exclusion of patients with chronic kidney disease from clinical trials in coronary artery disease. Kidney Int 2006;70:2021-2030.

-28 Coca SG, Krumholz HM, Garg AX, Parikh CR: Underrepresentation of renal disease in randomized controlled trials of cardiovascular disease. JAMA 2006;296:13771384. 